\title{
O bibliotecário e o analfabetismo no Brasil
}

\author{
Murilo Bastos da Cunha \\ Universidade de Brasília, Faculdade de Ciência da Informação, Brasília, DF, Brasil \\ murilobc@unb.br
}

DOI: https://doi.org/10.26512/rici.v12.n3.2019.26984

Recebido/Recibido/Received: 2019-08-10

Aceitado/Aceptado/Accepted: 2019-09-05

Resumo: O editorial comenta a importância de se combater o analfabetismo no Brasil, bem como a necessidade de uma maior participação do bibliotecário e da biblioteca visando a redução dessa chaga social. Além disso, são comentados os artigos incluídos no terceiro número de 2019 da Revista IberoAmericana de Ciência da Informação.

Palavras-chave: Analfabetismo. Brasil. Biblioteca escolar. Biblioteca pública.

The librarian and illiteracy in Brazil

Abstract: The editorial comments on the importance of combating illiteracy in Brazil, as well as the need for greater participation by the librarian and the library to reduce such a social burden. In addition, the articles published in the third issue of 2019 of the Ibero-American Journal of Information Science are commented.

Keywords: Illiteracy. Brazil. School library. Public library.

El bibliotecario y el analfabetismo en Brasil

Resumen: Los comentarios editoriales sobre la importancia de combatir el analfabetismo en Brasil, así como la necesidad de una mayor participación del bibliotecario y la biblioteca para reducir esta carga social. Además, se comentan los artículos publicados en el tercer número de 2019 de la Revista Iberoamericana de Ciencias de la Información.

Palabras clave: analfabetismo. Brasil. Biblioteca pública. Biblioteca escolar.

\section{Caro leitor}

O professor Cristovam Buarque, ex-reitor da Universidade de Brasília, foi ministro da Educação entre 2003 e 2004, no primeiro mandato do Presidente Lula. Em seu discurso de posse no ministério o professor apontou como prioridade em sua gestão o combate ao analfabetismo ao afirmar:

[...] Mas agora quero fazer referência, com todo respeito às anteriores, ao mais importante: $\mathrm{o}$ analfabeto brasileiro. Quero fazer uma referência aos 20 milhões de brasileiros, que não temos o direito de daqui a quatro anos, termos ainda iletrados. É o desafio que eu assumo aqui. [...] Não é possível que um país que tem a mesma língua, fabrica aviões, tem hidrelétricas, tem tanta riqueza, não consiga fazer com que todos os adultos leiam a língua, que quase todos falam, salvo alguns grupos indígenas. Não é possível. É uma vergonha, que nós não temos o direito de viver com ela e muito menos de deixá-la para gerações que venham diante de nós. Nós herdamos um Brasil 
com analfabetos. Mas por favor, não repassemos para os nossos filhos e netos, para gerações futuras, um Brasil com a chaga do analfabetismo. Esse é o desafio que eu quero convocar todos. Ninguém pode ficar de fora. (Leia, 2003; grifo nosso)

Infelizmente, por discordância política o Professor Cristovam saiu do ministério em 2004, retornando à sua cadeira no Senado Federal e a temática do combate ao analfabetismo perdeu um grande aliado e ficou esquecida. Quinze anos depois, em 2019, a chaga do analfabetismo ainda continua viva no Brasil. A mais recente taxa de analfabetização, divulgada pelo IBGE em junho de 2019, na Pesquisa por Amostra de Domicílios Contínua (IBGE, 2019), apontou que o nosso país tem pelo menos 11,3 milhões de pessoas analfabetas com mais de 15 anos. O país reduziu a analfabetização, mas não na velocidade esperada: ainda não alcançou a meta do Plano Nacional de Educação para 2015, que era baixar o índice para 6,5\%, a fim de erradicar o analfabetismo até 2024.

De acordo com o Centro de Alfabetização, Leitura e Escrita (CEALE), da Universidade Federal de Minas Gerais (UFMG), analfabeta é qualquer pessoa que não conheça o alfabeto ou que não saiba ler e escrever, e analfabetismo, a condição de quem não conheça o alfabeto ou não saiba ler e escrever. A taxa de analfabetismo medida pelo IBGE é o porcentual de pessoas que não sabem ler e escrever pelo menos um bilhete simples, no idioma que conhecem, na população total residente da mesma faixa etária, em determinado espaço geográfico, no ano considerado.

Ao lado do conceito analfabeto também existe o chamado "analfabeto funcional" é o indivíduo que sabe ler e escrever, mas não é capaz de entender ou interpretar um texto que acabou de ler ou mesmo executar a contento a linguagem para nas tarefas cotidianas. Para o IBGE, a taxa de analfabetismo funcional é a porcentagem de pessoas de uma determinada faixa etária que tem escolaridade de até três anos de estudo em relação ao total de pessoas na mesma faixa etária. Há uma outra métrica, criada pela ONG Ação Educativa (AÇÂO, 2018) em parceria com o Instituto Paulo Monteiro (do IBOPE), o Índice Nacional de Analfabetismo Funcional (INAF). O INAF Brasil 2018 apontou que cerca de 30\% dos brasileiros entre 15 e 64 anos são analfabetos funcionais, também mostrou que:

(...) Ao longo dos anos, houve ainda uma redução da proporção de brasileiros que conseguem fazer uso da leitura da escrita e das operações matemáticas em suas tarefas do cotidiano apenas em nível Rudimentar (de 27\% em 20012002 para um patamar estabilizado de pouco mais de $20 \%$ desde 2009 ). Indivíduos classificados nesses dois níveis de Alfabetismo compõem um grupo denominado pelo INAF como Analfabetos Funcionais. Os Analfabetos Funcionais - equivalentes, em 2018, a cerca de 3 em cada 10 brasileiros têm muita dificuldade para fazer uso da leitura e da escrita e das operações matemáticas em situações da vida cotidiana, como reconhecer informações em um cartaz ou folheto ou ainda fazer operações aritméticas simples com valores de grandeza superior às centenas. (AÇÃO, 2018, p. 8; grifo nosso) 
O que os dados acima querem dizer? Numa análise rápida, esses dados demonstram que na população brasileira estimada pelo IBGE (IBGE, 2019), em agosto de 2019, num total de 210 milhões de habitantes, existem cerca de 11 milhões de analfabetos e 63 milhões de analfabetos funcionais. Isto é um dado alarmante; só o total de analfabetos equivale, por exemplo, a um Portugal e quase quatro Uruguais!

Os dados são preocupantes e, voltando à fala do Professor Cristovam, alguma coisa precisa ser feita e "ninguém pode ficar de fora". No que tange ao profissional bibliotecário este tipo de chamada já foi feito no passado. O bibliotecário e professor Peter Harvard-Willians, da Loughborough University of Technology, após a consultoria realizada para a CAPES, publicou quarenta e quatro anos atrás, um artigo intitulado "S.E.O.: a Biblioteconomia no Brasil". Nesse documento (1975, p. 14) ele "cutucou" os colegas brasileiros quando indagou:

Se o Ministro da Educação e Cultura solicitasse a vocês que o aconselhassem, o que the diriam? Pois a sua responsabilidade, como bibliotecáriodocumentalista-arquivista brasileiro, é formular as respostas. Minha não é, pois posso apenas colocar algumas perguntas. A propósito, que farão vocês, também, como bibliotecários, com relação ao problema do analfabetismo? Não conheço a resposta, mas gostaria de saber qual é. Talvez vocês me respondam (e a outros) num futuro número desta revista. (grifo nosso)

A resposta do bibliotecário brasileiro ao desafio proposto por Harvard-Williams tem sido muito pequena. Numa busca realizada na Base de Dados Referenciais de Artigos de Periódicos em Ciência da Informação (BRAPCl, 2019) utilizando-se o termo "analfabetismo" no campo de resumo foram recuperados 22 documentos publicados no período de 1972 a 2019. 0 resultado da busca indica que o número de itens recuperados é muito pouco comparado com o total de 19.255 documentos indexados por essa base de dados. Isto vem reforçar a ideia de que o tema despertou pouco interesse entre os profissionais da Biblioteconomia.

A seguir será feita uma análise de alguns desses documentos identificados. lara Ferreira de Macedo, bibliotecária da Universidade Federal do Rio Grande do Sul, apontou, em 1987, que

Sabe-se que um pré-requisito básico para o desenvolvimento da leitura numa sociedade refere-se à formação de leitores através do processo de alfabetização. Mas, vale ressaltar, que apesar de ser um elemento fundamental, a alfabetização não é suficiente em si mesma para garantir a evolução da leitura numa sociedade. Com isto quer se dizer, de que adianta saber ler se os objetivos da leitura (livros, jornais, revistas, etc.) não são colocados a disposição do indivíduo, ou, até mesmo, não há dinheiro para a compra, De que adianta saber ler se não existe uma leitura no mundo (...) (MACEDO, 1987, p. 53; grifo nosso)

Rubens da Silva Ferreira, graduado em Biblioteconomia pela Universidade Federal do Pará, num estudo sobre a sociedade da informação no Brasil, apontou o analfabetismo como um dos fatores críticos para que o Estado possa alcançar resultados na implementação dessa nova sociedade. Para o autor 
(...) o analfabetismo é o maior desafio a ser enfrentado pelo Estado para a consolidação de uma sociedade da informação no Brasil, uma vez que os estoques de informação disponíveis na Internet encontram-se, em sua maioria, sob a forma de texto escrito, inacessíveis para cerca de 20 milhões de brasileiros que não sabem ler e escrever (Baggio, 2000). Este desafio evidencia, portanto, que a educação ainda é a melhor via para que um país alavanque seu processo de desenvolvimento, com maiores possibilidades de inclusão e igualdade de oportunidades para o cidadão. (FERREIRA, 2003, p. 38; grifo nosso)

Flávia Rosa e Nanci Oddone, da Universidade Federal da Bahia, em 2006, fizeram uma análise crítica das políticas públicas nacionais para o livro, a leitura e as bibliotecas. As autoras (ROSA et al., 2006, p. 185); ponderaram que

Transformar o Brasil em um país de leitores não é tarefa fácil, sobretudo no contexto da sociedade da informação, no qual novos suportes informacionais direcionam as políticas não apenas para as práticas leitoras e para a alfabetização cidadã, mas principalmente para o domínio das novas tecnologias, muitas vezes distantes da formação do cidadão leitor e apenas instrumentalizadoras de habilidades primárias que têm como objetivo incluir o cidadão nessa sociedade. (grifo nosso)

Um relacionamento entre a inclusão digital e o analfabetismo foi apontado pela professora Sofia G. Baptista, da Universidade de Brasília. Para ela

\begin{abstract}
No Brasil, não é viável enfrentar a inclusão digital sem levar em conta o alto analfabetismo. Embora o país conte com a participação de vários segmentos da sociedade, os recursos governamentais ainda são insuficientes. Sem contar que os recursos humanos também são escassos, pois os profissionais da área não atuam diretamente na promoção da educação e do bem-estar social. Por formação, o bibliotecário é altamente qualificado para desempenhar o papel social que promova a cidadania em comunidades carentes. Porém, são poucos os que se interessam pela área, já que não há retorno quanto à remuneração, e a infraestrutura oferecida é desfavorável para uma atuação efetiva. (BAPTISTA, 2006, p. 29; grifos nossos)
\end{abstract}

Como se pode notar pelos pensamentos dos autores citados anteriormente, há necessidade de que "ninguém pode ficar de fora" no combate à redução do analfabetismo no Brasil. Com essa redução também será possível reduzir a taxa de analfabetismo digital e, quem sabe, ampliar o nível do letramento em informação dos brasileiros. O bibliotecário não pode continuar passivo, ele deve pressionar todos os níveis de atuação governamental (municipal, estadual e federal), das instituições privadas e organizações do Terceiro Setor. Essa pressão deve ser voltada para a melhoria e ampliação das políticas públicas voltada ao combate do analfabetismo. É claro que, além disso, o profissional deve mostrar a importância das bibliotecas públicas e escolares como locais adequados para receberem os futuros cidadãos que poderão ler e escrever. Há, portanto, um longo caminho a ser percorrido pelo bibliotecário e suas entidades profissionais.

Neste último número da RICl em 2019, foram selecionados para publicação 13 artigos, dois artigos de revisão de literatura, um ensaio e um documento. 
Boa leitura e até o nosso próximo número!

\section{Referências}

AÇÃO EDUCATIVA; INSTITUTO PAULO MONTENEGRO. INAF BRASIL 2018:resultados preliminares. São Paulo, 2018. 22 p. Disponível em: $<$ http://acaoeducativa.org.br/wpcontent/uploads/2018/08/Inaf2018 Relat\%C3\%B3rio-ResultadosPreliminares v08Ago2018.pdf > Acesso em 10 de agosto de 2019.

BAPTISTA, Sofia Galvão. A inclusão digital: programas governamentais e o profissional da informação - reflexões. Inclusão Social, Brasília, v. 1, n. 2, p. 23-30, abr./set. 2006.

BASE de Dados Referenciais de Artigos de Periódicos em Ciência da Informação (BRAPCI). Disponível em: $<$ http://www.brapci.inf.br/?q=analfabetismo\&type=5\&year s=1972\&year e=2019 > Acesso em: 12 de agosto de 2019.

FERREIRA, Rubens da Silva. A sociedade da informação no Brasil: um ensaio sobre os desafios do Estado. Ciência da Informação, v. 32, n. 1, p. 36-41, jan./abr. 2003.

HAVARD-WILLIAMS, Peter. S.E.O.: A Biblioteconomia no Brasil. Revista de Biblioteconomia de Brasília, v. 3, n. 1, p. 3-15, jan./jun. 1975.

HOLANDA, Ariosto. Atalhos para o resgate da cidadania. Inclusão Social, Brasília, v. 2, n. 1, p. 6066, out. 2006/mar. 2007.

IBGE. Pesquisa Nacional por Amostra de Domicílios - PNAD. Disponível em: $<$ https://www.ibge.gov.br/estatisticas/sociais/educacao/9127-pesquisa-nacional-por-amostrade-domicilios.html?=\&t=o-que-e $>$ Acesso em: 10 agosto 2019.

IBGE. População do Brasil. Disponível em: $<$ https://www.ibge.gov.br/apps/populacao/projecao/box popclock.php > Acesso em: $13 \mathrm{de}$ agosto de 2019.

LEIA íntegra do discurso de Cristovam Buarque, ministro da Educação. Folha de S. Paulo, 3 jan. 2003. Disponível em: <https://www1.folha.uol.com.br/folha/brasil/ult96u44399.shtml > Acesso em: 12 agosto de 2019.

MACEDO, lara Ferreira de. O livro e a leitura no Brasil: algumas ideias alternativas. Revista de Biblioteconomia e Comunicação, Porto Alegre, v. 2, p. 52-57, jan./dez. 1987.

ROSA, Flavia Goulart Mota Garcia; ODDONE, Nancy. Políticas públicas para o livro, leitura e biblioteca. Ciência da Informação, Brasília, v. 35, n. 3, p. 183-193, set./dez. 2006.

UNIVERSIDADE FEDERAL DE MINAS GERAIS (UFMG). Faculdade de Educação. Centro de Alfabetização, Leitura e Escrita (Ceale). Glossário Ceale: termos de alfabetização, leitura e escrita para educadores. Belo Horizonte, 2014. Disponível em:

<http://www.ceale.fae.ufmg.br/app/webroot/glossarioceale/ > Acesso em: 13 agosto 2019. 